\title{
From 63 to 400?
}

Colin Norman in Washington examines the implications for nuclear power of last week's energy proposals from President Carter

"This has been an exceptional week", President Carter declared last Friday during a packed press conference. Indeed it has. It began with a sombre televised address in which $\mathrm{Mr}$ Carter suggested that overcoming the energy "problem" would be a little like waging a war, and ended with a press conference in which he defended his strategy for winning that war. The strategy itself was unveiled on Wednesday, and it has so far achieved the distinction of uniting commentators in their observations that dramatic measures may be needed, but that some of Carter's measures should be resisted.

The strategy consists of a bold set of measures designed to curb Americans' seemingly insatiable appetite for energy by raising energy prices, taxing heavy users, and returning the revenues back into the economy in the form of rewards to people who conserve (see box). The plan is also designed to decouple industry from its reliance on oil and gas by forcing more widespread use of coal, and it also attempts to encourage the use of light water reactors. The emphasis is on the near term.

The proposals for nuclear power are particularly interesting. On April 7, Carter announced that, in the interests of curbing nuclear proliferation, the Administration will defer indefinitely its plans to reprocess commercial nuclear fuel and that it will sharply downgrade the breeder reactor programme. Last week, those decisions were spelled out in more detail, but at the same time, Carter made it clear that the Administration does not intend to turn its back on nuclear power. Far from it. Carter in fact announced that the Administration will seek to remove some of the roadblocks to licencing nuclear plants, step up attempts to find suitable burial sites for nuclear wastes, and completely change direction on uranium enrichment by building a large new enrichment plant using gas centrifuge technology instead of the present gaseous diffusion process.

The intention, in short, is to rely on light water reactors, without plutonium recycle, to meet a growing share of energy needs for at least the next 25 years, but to keep the breeder reactor effort ticking over as insurance against the possibility that the United States will nced to move into the plutonium economy early in the next century. According to officials of the Energy Research and Development Administration (ERDA), the number of light water reactors in the United States is expected to grow steadily from the present figure of 63 to between 300 and 400 by the turn of the century.

The nuclear strategy rests on some critical assumptions, however, perhaps the most important of which involves the size of the United States' uranium reserves. Proven reserves now amount to about 1.8 million tons, which would be sufficient to fuel about 300 reactors throughout their lifetimes-barely enough to meet ERDA's projections for domestic nuclear expansion this century, with none left over to meet contracts from abroad. ERDA is, however, launching an intensive programme to assess uranium reserves more accurately, and acting ERDA Administrator Robert Fri said last week that he is "guardedly optimistic" that proven reserves will swell to about 3.7 million tons. There is some question, however, whether the electricity in-

The central feature of President Carter's energy strategy is a carrot-and-stick arrangement of rewards and penalties designed to break the country's addiction to vast quantities of energy. The carrot comes in the form of an assortment of tax breaks and other financial incentives for people who insulate their homes, buy small cars or install solar heaters. The stick is a complex set of proposals which will lead to higher energy prices, and the threat of stiff taxes on gasoline and on gas-guzzling cars. The goal is to reduce the growth in energy demand from its present level of about $3.5 \%$ a year to about $2 \%$

Coupled with those efforts to stimulate conservation is a series of proposals designed to increase the use of coal and light water reactors. Longer-term energy supply options will also receive modest increases in research support, but the emphasis is mostly on efforts likely to produce relatively quick results.

The major elements of the plan:

Oil and gas prices: $A$ complex set of taxes coupled with price increases for newly-discovered domestic crude oil would cause oil and gas prices to increase until they "generally reflect the true replacement cost of energy". At present, prices are kept artificially low by a variety of controls.

Gasoline taxes: Unless gasoline consumption is reduced according to specific targets, tax increases of 5 cents per gallon will be imposed each year, beginning in 1979, until the total tax reaches a maximum of 50 cents.

Gas guzzler taxes: New cars which fail to meet gasoline consumption standards would be heavily taxed, and the revenues would be returned in the form of rebates to people who buy more efficient cars. dustry, faced with uncertainties in long-term uranium supply and with no guarantee that plutonium recycle will be available to help stretch nuclear fuel supplies, will be enthusiastic about purchasing nuclear plants.

As for the breeder reactor programme, there is still some confusion about the Administration's intentions. One thing is certain, however: the effort is being sharply cut back and it no longer occupies pride of place as the top priority programme in the United States' energy research and development effort. Last week, Carter proposed that the programme's budget be reduced by $\$ 173$ million next year, in addition to a cut of nearly $\$ 200$ million which he proposed in February. The plan now is to complete the fast flux test facility, a test reactor now under construction in Washington, but to defer indefinitely plans to build a large demonstration reactor on the Clinch River in Tennessee. That project, which was to have cost more than $\$ 2,000$ million, will be redirected to focus on alternative breeder reactor designs which present less of a proliferation hazard. The exact nature of the programme has not yet been

For example, 1978 model cars which get less than 12.5 miles per gallon would carry a tax of $\$ 449$, while those which get more than 39 miles per gallon would be given a rebate of $\$ 473$. By 1985 , cars with those consumption levels would carry taxes and rebates of $\$ 2,488$ and $\$ 493$ respectively.

Insulation and Solar heating: All new buildings will have to meet insulation standards. Homeowners who insulate their houses would be entitled to income tax credits of $25 \%$ of the first $\$ 800$ and $14 \%$ of the next $\$ 1,400$ spent on conservation measures. Similarly, people who install solar equipment before 1985 would be able to claim $40 \%$ of the first $\$ 1,000$ and $25 \%$ of the next $\$ 6,400$ as a tax credit.

Nuclear power: Light water reactors without plutonium recycle will have an increasingly large role. New gas centrifuge plants will be built to enrich uranium for reactor fuels, more funds will be pumped into efforts to find suitable waste disposal sites, and an attempt will be made to reduce the present10-year licencing process for nuclear plants to 3 years.

Coal: Many industrial facilities would be forced to switch from oil and gas to coal, and they would also be required to use the best available technology to control pollutants. Research and development on processes designed to produce synthetic oil and gas from coal would be stepped up. In addition, Carter will establish a commission to report by October this year on the health effects associated with mining and burning large quantities of coal. And a new research programme, costing \$3 million, will be launched to look into the so-called greenhouse effect. 
worked out, however, and Administration officials suggest that it will be weeks, if not months, before it is.

As for the plan to build a large centrifuge enrichmenmt plant, this again is coupled with Carter's moves to curb nuclear proliferation. In 1974, the United States closed its order books for long-term supplies of enriched uranium to other countries because of projections that US enrichment capacity would be used up. The move is said to have prompted many countries to seek alternative sources of supply, and it may have been a key factor in persuading Brazil to negotiate the purchase of an enrichment plant from West Germany. Carter has therefore announced that the United States will re-open its order books, and that a supply of enriched uranium will be guaranteed to those countries which renounce the development of nuclear weapons.

To meet the projected demand, a large centrifuge enrichment plant will be constructed at a cost of some $\$ 4,400$ million. So far, all US enrichment has used the gaseous diffusion process, and previous plans called for expansion of an existing diffusion plant at Portsmouth, Ohio. Administration officials say, however, that the gas centrifuge process, which has been developed in secrecy at Oak Ridge, Tennessee, is now ready to be commercialised. So far, however, no site for the new plant has been chosen, though hints that it may go to Oak Ridge, to compensate for cancellation of the breeder reactor project there, have sparked loud protests in Portsmouth.

In addition to relying on a modest expansion of nuclear generating capacity, Carter's plans for medium-term energy supply also envisage considerable expansion in the use of coal. $\mathrm{He}$ has proposed measures to force industry to convert from oil and gas to coal, announced large increases in research and development efforts aimed at producing synthetic oil and gas from coal, and recommended a number of regulations to reduce the environmental consequences of such an expansion.

There is, however, one potential environmental problem which could prove intractable: the so-called greenhouse effect which may lead to changes in the global climate from large increases in atmospheric carbon dioxide. Carter announced last week that a major study of the greenhouse effect, costing $\$ 3$ million, will be launched this year.

Carter's energy plan will now be picked over on Capital Hill, and already special interest groups are clawing at it. The debate is likely to rage for the rest of this year.

GEOS

\section{Hope from despair?}

Stuart Sharrock in Washington and Chris Sherwell in London report on the ill-starred launch of Geos, the European Space Agency's scientific satellite

ON Tuesday of this week a group of space scientists and another of space engineers met separately on opposite sides of the Earth to discuss an event that occurred above the globe halfway between them. Last Wednesday, twenty minutes after a Thor-Delta 2914 rocket had taken off from Cape Canaveral only 0.2 seconds later than its scheduled lift-off of 05.15 , the hopes of 11 research institutes from eight member countries of the European Space Agency turned to despair as a malfunction during the separation of the second and third stages of the rocket caused the third stage to separate early. It meant that the payload, the world's first geostationary scientific satellite known as Geos, could not achieve its planned orbit and that seven experiments which took years to prepare might no longer be done.

In fact the despair looks as though it may have been premature. For although the engineers from the rocket manufacturers McDonnell Douglas gathered in California to discuss the Delta's acknowledged failure, the scientists who met at the ESA's Space Operations Centre at Darmstadt in West Germany did so a little more optimistically. On the previous day Geos had been placed in an elliptical orbit whose apogee, at $38,498 \mathrm{~km}$, was easily as high as the originally intended circular orbit.

The difference, of course, was that the new orbit, not heing geostationary, would not allow the satellite to be permanently within sight of the Darmstadt ground station. It is understood, however, that not all the data obtained over each 24-hour period would have been used anyway. The new elliptical orbit, selected to maximise the return of scientific data, has a perigee of $2,131 \mathrm{~km}$ and an inclination of $26.85^{\circ}$. It is traversed every 12.06 hours by the satellite, which could now be within sight for some 10 hours a day.

As the scientists gathered to decide which experiments to pursue and data to collect, ESA officials were pleased to have retrieved, if only partially, a mission which at first looked on the very edge of disaster. The spacecraft and third stage assembly should have spun up to 97 revolutions per minute before separating from the second stage. This spin stabilisation would have ensured that the third stage had an accurate trajectory during its burn; without it, the spacecraft tumbled around into the wrong orbit, though it was stabilised soon thereafter.

The spacecraft could not have been allowed to stay indefinitely in this socalled transfer orbit because it went through zones of high radiation which might endanger the experiments and decrease the total active lifetime of the spacecraft. To stay in that orbit also served no useful purpose: it was not on the magnetic field lines connected to the auroral zones of the Arctic and Antarctic, and the experiments would probably not work with the field and particle intensities so high.

The original intention was that the spacecraft should be injected into an elliptical transfer orbit (apogee 35,500 $\mathrm{km}$, perigee $230 \mathrm{~km}$ ) and then be boosted on the fourth apogee to a circular orbit synchronised with the Earth below. That the European-built solid-propellant apogee booster motor responsible for this task placed Geos in the elliptical orbit it now occupies is a cause for comfort, even though the motor could not be used twice to achieve a circular orbit. But then so much could so easily have gone wrong.

The effect, ironically, is that Geos is now placed in a fashion that had been expected of the ESA's spare 'qualification' geosynchronous satellite which was due to be sent up in 1979 atop a European Ariane launcher now being developed. It remains possible that this back-up satellite will be upgraded to become the 'true Geos', but it will cost the ESA another 13 million units of account to purchase the launch from NASA - a cost which is not recoverable for last week's launch under NASA's no-loss-no-profit contracts. Although the ESA Council is due to meet next week, it is unlikely to discuss this idea of inverting the roles of the two satellites.

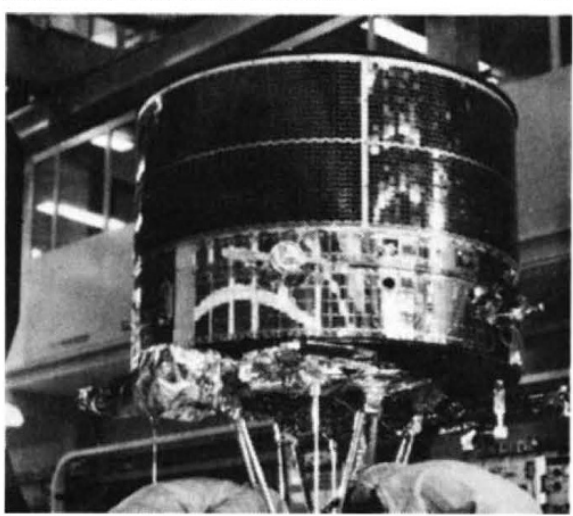

